\begin{tabular}{cll} 
Cellular Physiology & Cell Physiol Biochem 2012;30:83-94 & \\
\cline { 2 - 3 } and Biochemistry 10.1159/000339043 & $\begin{array}{l}\text { O 2012 S. Karger AG, Basel } \\
\text { www.karger.com/cpb }\end{array}$ \\
\cline { 2 - 3 } & $\begin{array}{l}\text { Published online: June 08, 2012 } \\
\text { Accepted: April 11, 2012 }\end{array}$ & $1015-8987 / 12 / 0301-0083 \$ 38.00 / 0$
\end{tabular}

\title{
Rat Cardiac Mitochondrial Sub-populations Show Distinct Features of Oxidative Phosphorylation during Ischemia, Reperfusion and Ischemic Preconditioning
}

\author{
Gino A Kurian ${ }^{1}$ Eduard Berenshtein ${ }^{1} \quad$ Ann Saada $^{2} \quad$ Mordechai Chevion $^{1}$ \\ ${ }^{1}$ Department of Cellular Biochemistry and Human Genetics, ${ }^{2}$ Department of Genetics and Metabolic \\ Diseases, The Hebrew University-Hadassah Schools of Medicine and Dental Medicine, Jerusalem
}

\section{Key Words}

Inter-fibrillar mitochondria $\cdot$ Sub-sarcolemmal mitochondria $\bullet$ Myocardial ischemia reperfusion - Ischemic preconditioning • Electron transport chain enzymes

\begin{abstract}
Background: Inter-fibrillar (IFM) and sub-sarcolemmal (SSM) mitochondria are two distinct mitochondrial sub-populations and are expected to behave differently during pathological conditions. This study was undertaken to compare functional oxidative phosphorylation (OXPHOS) in IFM and SSM during ischemia, reperfusion and ischemic preconditioning. Methods: Langendorff perfused Wistar rat hearts were subjected to 35 minutes ischemia, 60 minutes reperfusion and ischemic preconditioning (IPC) procedure (3cycles of 2-minutes ischemia followed by 3-minutes reperfusion).Subsequently IFM and SSM were isolated, and mitochondrial electron transport chain (ETC) enzyme activities and respiration were measured immediately. Results: Functional enzyme activities of ETC in IFM and SSM showed prominent differences especially in the proximal part of ETC enzymes during ischemia and reperfusion. SSM favor FADH $\mathrm{H}_{2}$ while IFM prefer NADH as the main reducing equivalent for electron transport during ischemia and reperfusion. IPC preserved ETC enzyme activities in both IFM and SSM rendering cardio protection. Similarly IPC preserve ADP stimulated respiration with glutamate and malate as substrate in both sub populations, but not in IFM, with succinate as substrate. Apparently, the preconditioning imparts enhanced protection more to SSM than IFM during ischemia and reperfusion and especially to the proximal part of the ETC. Conclusion: We propose that mitochondrial dysfunction, one of the major targets of myocardial ischemia reperfusion injury needs to be evaluated by the synergic effect of both IFM and SSM.
\end{abstract}




\section{Cellular Physiology $\quad$ Cell Physiol Biochem 2012;30:83-94 \begin{tabular}{l|l}
\hline DOI: $10.1159 / 000339043$ & C 2012 S. Karger AG, Basel
\end{tabular} and Biochemistry \\ Kurian/Berenshtein/Saada/Chevion: Mitochondrial Subpopulation and Cardiac Ischemia Reperfusion Injury}

\section{Introduction}

Both myocardial ischemia and reperfusion targets mitochondria as the site of injury, resulting in oxidative damage, the onset of mitochondrial permeability transition, and the activation of apoptotic cascades, leading to cardiomyocyte death [1,2]. A substantial portion of damage to mitochondrial electron transport and OXPHOS was surprisingly reported to occur during ischemia, rather than in reperfusion [3]. In early periods of ischemia, previous studies demonstrated decreased complex I activity damage to the phosphorylation apparatus, including complex $\mathrm{V}$ and the adenine nucleotide transporter [4-6]. As ischemic periods prolong, oxidative phosphorylation through complex III and cytochrome c oxidase decreases $[7,8]$.

On the contrary Sako et al. reported that, despite the reduced mechanical function and increased myocardial oxygen consumption rate, the ratio of net ATP synthesis by oxidative phosphorylation to oxygen consumption rate (the P:O ratio) was not altered subsequent to ischemia [9]. Similarly in another study, isolated mitochondria from perfused rat hearts subjected to hypoxia found no change in their respiratory function relative to controls [10]. Thus, the various studies show conflicting data in which ischemia/reperfusion in heart respiration may increase, decrease or remain unaltered. The different results emphasize the need for further energetic studies in this perspective.

Recent studies suggests that mitochondria localized in different regions of cell may display different morphology, dissimilar biochemical properties, or may differently interact with other intracellular structures [11]. Cardiac mitochondria comprise two sub-populations namely sub sarcolemmal (SSM) and interfibrillar mitochondria (IFM). SSM located close to plasma membrane are proposed to be important for functional coupling to ATP-driven ion pumps and may also serve as protective barrier against high oxygen concentration outside the cell [12]. Most of the cited studies used mitochondrial isolation procedure that yields largely SSM. Consequently the IFM, which provide most of the energy to the contractile apparatus, were under-represented to a variable degree, possibly being the source of conflicting results. In the present study, we aimed to examine the influence of ischemia reperfusion to individual, defined mitochondrial sub-populations. We separated both IFM and SSM from isolated rat heart and examined on each sub fraction, the impact of ischemia, reperfusion and ischemic preconditioning on OXPHOS.

\section{Materials and Methods}

\section{Animals and experimental design}

Wistar male rats (250-300 g) were housed under standard conditions and fed regular ad libitum diet and water. All the experimental protocols were approved by the 'Institutional Animal Care and Use Committee' of the Hebrew University of Jerusalem, conforming to the Guide for the Care and Use of Laboratory Animals published by the U.S. National Institutes of Health (NIH Publication No. 85-23, revised 1996).

\section{Perfusion protocols}

Hearts were removed and mounted on the Langendorff apparatus as previously described by us [13]. Hearts were perfused by protocols showed in the Fig. 1A.

Cardiac functional changes caused by ischemia and reperfusion are shown in Fig. 1B. The sample trace of left ventricle pressure shows the development of hyper-contracture during ischemia (arrow).

\section{Experimental groups}

Rats were randomly divided into 4 main groups; control, ischemia (I), reperfusion (I/ R) and ischemic preconditioning (IPC) groups. Control groups were subdivided into three subgroups. Isolated hearts from three control sub groups were subjected to continuous perfusion of Krebs Henseleit (KH) buffer for 25 minutes ( P25), 60 minutes (P60) and 120 minutes (P120). In the other groups, isolated rat hearts were stabilized for 10minutes in IPC and 25 minutes in I and I/R to establish its baseline parameters as a reference 


\section{Cellular Physiology Cell Physiol Biochem 2012;30:83-94 \begin{tabular}{ll|l} 
and Biochemistry & $\begin{array}{l}\text { DOI: 10.1159/000339043 } \\
\text { Published online: June 08, 2012 }\end{array}$ & $\begin{array}{l}\text { C 2012 S. Karger AG, Basel } \\
\text { www.karger.com/cpb }\end{array}$ \\
\hline $\begin{array}{l}\text { Kurian/Berenshtein/Saada/Chevion: Mitochondrial Subpopulation and Cardiac Ischemia } \\
\text { Reperfusion Injury }\end{array}$
\end{tabular}}

to the effects caused by subsequent manipulations. In the I group, hearts were subjected to 35 minutes of global ischemia after stabilization. Similarly in I/R group, 35 minutes global ischemia was induced followed by 60 minutes reperfusion after stabilization. Ischemic preconditioning group was subdivided into three subgroups namely, IPC, IPC +I \& IPC +IR. In the IPC group, after stabilization, isolated rat hearts were subjected to three cycles of 2 minutes ischemia followed by 3 minutes reperfusion. In IPC + I and IPC + IR groups, same procedure mentioned for IPC was followed but subsequently 35 minutes of global ischemia was induced in IPC +I group whereas 35 minutes global ischemia followed by 60 minutes reperfusion was induced in IPC +IR groups. The hemodynamic parameters were monitored throughout the entire duration of each experiment, typically 120 minutes. The biochemical parameters were measured in heart tissue samples taken at pre-determined time points along the protocol. At these time points, the heart was quickly frozen in liquid nitrogen and kept at $-80^{\circ} \mathrm{C}$ until analyzed.

The following hemodynamic parameters were evaluated: left ventricle peak systolic pressure (PSP), end diastolic pressure (EDP), developed pressure (DP = PSP- E DP), heart rate (HR), work index (WI = DP $\times$ $\mathrm{HR}),+(\mathrm{dp} / \mathrm{dt})_{\max }($ denoted $+\mathrm{dp} / \mathrm{dt})$ and $\left.-\mathrm{dp} / \mathrm{dt}\right)_{\max }($ denoted $-\mathrm{dp} / \mathrm{dt})$.

\section{Isolation of mitochondrial sub population}

Rat heart mitochondria were isolated by differential centrifugation, essentially according to the method described by Palmer et al. [14].

Isolation of sub-sarcolemmal mitochondria: Briefly, the cardiac tissues were homogenized in medium containing $100 \mathrm{mM} \mathrm{KCl}, 40 \mathrm{mM}$ Tris $\mathrm{HCl}$ : pH 7.5, $10 \mathrm{mM}$ Tris base, $5 \mathrm{mM} \mathrm{MgCl}{ }_{2}, 1 \mathrm{mM}$ EDTA, $1 \mathrm{mM}$ ATP in a proportion of $10 \mathrm{ml} / \mathrm{g}$ heart. The homogenate was centrifuged at low speed $\left(800 \mathrm{x} \mathrm{g}\right.$ for 5 minutes at $\left.4^{\circ} \mathrm{C}\right)$, the resultant supernatant was transferred to a clean tube and centrifuged at high speed $(9000 \mathrm{x} g$ for 10 minutes at $4^{\circ} \mathrm{C}$ ). The resulting pellet was suspended in solution containing $100 \mathrm{mM} \mathrm{KCl}, 10 \mathrm{mM}$ Tris $\mathrm{HCl}$ : pH 7.4, 10mM Tris base, $1 \mathrm{mM} \mathrm{MgSO}_{4}, 0.1 \mathrm{mM}$ EDTA, $0.02 \mathrm{mM}$ ATP and 1.5\% BSA (free fatty acid free) and centrifuged at $8000 \mathrm{x}$ g for 10 minutes. The pellet obtained was resuspended in solution containing $100 \mathrm{mM}$ $\mathrm{KCl}, 10 \mathrm{mM}$ Tris HCl: $\mathrm{pH} 7.4,10 \mathrm{mM}$ Tris base, $1 \mathrm{mM} \mathrm{MgSO}_{4}, 0.1 \mathrm{mM}$ EDTA and $0.02 \mathrm{mM}$ ATP and re-centrifuged at $6000 \mathrm{x}$ g for 10 minutes. The pellet was collected and suspended in $220 \mathrm{mM}$ sucrose, $70 \mathrm{mM}$ mannitol, $10 \mathrm{mM}$ Tris $\mathrm{HCl}, \mathrm{pH} 7.4$ and $1 \mathrm{mM}$ EDTA.

Isolation of inter-fibrilar mitochondria: Cardiac tissues were homogenized and centrifuged as above. The resultant pellet was resuspended in the same solution (10fold) and homogenized for 5 seconds and re-centrifuged at low speed. The pellet was resuspended and trypsin was added at a concentration of $5 \mathrm{mg} /$ g wet tissue for 10 minutes at $4^{\circ} \mathrm{C}$. The reaction was stopped by adding 20 fold of same buffer and the suspension was centrifuged for 5 minutes at $5000 \mathrm{x}$ g. The resulting pellet was homogenized in solution containing $100 \mathrm{mM} \mathrm{KCl}, 10 \mathrm{mM}$ Tris $\mathrm{HCl}$ : pH 7.4, $10 \mathrm{mM}$ Tris base, $1 \mathrm{mM} \mathrm{MgSO}$, $0.1 \mathrm{mM}$ EDTA, 0.02mM ATP and $1.5 \%$ BSA (free fatty acid free) and centrifuge at $800 \mathrm{x} \mathrm{g}$ for 10 minutes. The resultant supernatant was transferred to a clean tube to be spun at high speed $\left(9000 \mathrm{xg}\right.$ for 10 minutes at $\left.4^{\circ} \mathrm{C}\right)$. Clean the pellet by resuspended in solution containing $100 \mathrm{mM} \mathrm{KCl}, 10 \mathrm{mM}$ Tris $\mathrm{HCl}$ : $\mathrm{pH} 7.4,10 \mathrm{mM}$ Tris base, $1 \mathrm{mM} \mathrm{MgSO} 4^{\prime}$ $0.1 \mathrm{mM}$ EDTA and $0.02 \mathrm{mM}$ ATP. Centrifuge the tubes at $6000 \mathrm{x}$ g for 10 minutes. The pellet was collected and suspended in incubation buffer containing $220 \mathrm{mM}$ sucrose, $70 \mathrm{mM}$ mannitol, $10 \mathrm{mM}$ Tris $\mathrm{HCl}, \mathrm{pH} 7.4$ and $1 \mathrm{mM}$ EDTA.

IFM and SSM were purified using a $60 \%$ percoll gradient and western blot analysis of HSP 60 , the marker protein (data not included) against actin was used to determine the purity.

Mitochondrial oxidative phosphorylation

Oxygen consumption by mitochondria was measured using a Clarke type oxygen electrode at $37^{\circ} \mathrm{C}$. Mitochondria $(300 \mu \mathrm{g}$ mitochondrial protein) were incubated in respiration medium containing $0.5 \mathrm{mM}$ EGTA, $3 \mathrm{mM} \mathrm{MgCl}_{2}, 60 \mathrm{mM}$ potassium lactobionate, $20 \mathrm{mM}$ taurine, $10 \mathrm{mM} \mathrm{KH}_{2} \mathrm{PO}_{4}, 20 \mathrm{mM}$ HEPES, $110 \mathrm{mM}$ sucrose and $1 \mathrm{~g} / \mathrm{l}$ fatty acid free BSA at pH 7.4. Mitochondria were used immediately after isolation from tissue and respiration was measured with glutamate $(10 \mathrm{mM})$ and malate $(2 \mathrm{mM})$ as substrate or with succinate $10 \mathrm{mM}$ in the presence of rotenone $0.5 \mu \mathrm{M}$.

Electron transport chain enzyme activities

The activities of electron transport chain enzymes were assayed essentially as described by Barrientos [15]. 


\section{Cellular Physiology Cell Physiol Biochem 2012;30:83-94 \begin{tabular}{ll|l} 
and Biochemistry & $\begin{array}{l}\text { DOI: 10.1159/000339043 } \\
\text { Published online: June 08, 2012 }\end{array}$ & $\begin{array}{l}\text { ○ 2012 S. Karger AG, Basel } \\
\text { www.karger.com/cpb }\end{array}$ \\
\cline { 2 - 3 } Kurian/Berenshtein/Saada/Chevion: Mitochondrial Subpopulation and Cardiac Ischemia \\
Reperfusion Injury
\end{tabular} Reperfusion Injury}

Measurement of rotenone-sensitive NADH-decylubiquinone oxidoreductase (NQR): Complex I activity

The sub-mitochondria particles $(20-40 \mu \mathrm{g}$ protein) were lysed by osmotic shock in $800 \mu \mathrm{l}$ of water for 3 minutes at $37^{\circ} \mathrm{C}$ before adding reaction mixture consisting of $200 \mu \mathrm{l}$ of $50 \mathrm{mM}$ Tris $\mathrm{HCl}, \mathrm{pH} 8.0$, supplemented with $5 \mathrm{mg} / \mathrm{ml} \mathrm{BSA}, 0.8 \mathrm{mM}$ NADH (as donor), $240 \mu \mathrm{M} \mathrm{KCN}$, and $4 \mu \mathrm{M}$ antimycin A. The reaction was started by adding $50 \mu \mathrm{M}$ of the acceptor decylubiquinone and the activity was monitored spectrophotometrically at $340 \mathrm{~nm}$. After 3 minutes, $4 \mu \mathrm{M}$ rotenone was added and the monitoring was continued for an additional 3 minutes to measure the rotenone insensitive activity.

Measurement of rotenone-sensitive NADH-cytochrome c oxidoreductase activity (NCCR): Complex I + III activity

The sub-mitochondria particles $(20-40 \mu \mathrm{g}$ protein) were lysed by osmotic shock in $800 \mu$ l of water for 3 minutes at $37^{\circ} \mathrm{C}$ before adding reaction mixture. The reaction mixture containing $200 \mu \mathrm{l}$ of $50 \mathrm{mM}$ Tris $\mathrm{HCl}, \mathrm{pH}$ 8.0, supplemented with $5 \mathrm{mg} / \mathrm{ml} \mathrm{BSA}, 40 \mu \mathrm{M}$ oxidized cytochrome $c$ (acceptor), and $240 \mu \mathrm{M} \mathrm{KCN}$. The reaction was started by adding $0.8 \mathrm{mM}$ NADH as donor. Measure the activity at $550 \mathrm{~nm}$ for 3 minutes. After 3 minutes, $4 \mu \mathrm{M}$ rotenone was added and the monitoring was continued for an additional 3 minutes to measure the rotenone insensitive activity.

Measurement of succinate decylubiquinone DCPIP reductase (SQR): Complex II activity

In order to activate complex II, mitochondria (20 to $40 \mu \mathrm{g}$ of protein) were pre-incubated with $10 \mathrm{mM}$ succinate in $10 \mathrm{mM} \mathrm{KH}_{2} \mathrm{PO}_{4}(\mathrm{pH} 7.8), 2 \mathrm{mM}$ EDTA and $1 \mathrm{mg} / \mathrm{ml} \mathrm{BSA}$, after 10 minutes at $30^{\circ} \mathrm{C}, 80 \mu \mathrm{M} 2,6$ dichlorophenolindophenol (DCPIP) as acceptor, $4 \mu \mathrm{M}$ rotenone, and $0.2 \mathrm{mM}$ ATP was added. The reaction was started by adding $80 \mu \mathrm{M}$ decylubiquinone. The activity was measured for 5 minutes following the decrease in absorbance at $600 \mathrm{~nm}$ resulting from the reduction of DCPIP. After 5 minutes, $10 \mathrm{mM}$ malonate (competitive inhibitor) was added to inhibit the oxidation of succinate and the monitoring was continued for an additional 3 minutes to measure the specificity of the reaction.

Measurement of succinate cytochrome c reductase (SCCR): Complex II + III activity

In order to fully activate complex II, mitochondria (20 to $40 \mu \mathrm{g}$ of protein) were pre-incubated with $10 \mathrm{mM}$ succinate in $10 \mathrm{mM} \mathrm{KH}_{2} \mathrm{PO}_{2}$ (pH 7.8), $2 \mathrm{mM}$ EDTA and $1 \mathrm{mg} / \mathrm{ml} \mathrm{BSA}, 240 \mu \mathrm{M} \mathrm{KCN}, 4 \mu \mathrm{M}$ rotenone, and $0.2 \mathrm{mM}$ ATP for 10 minutes at $30^{\circ} \mathrm{C}$. The reaction was started by adding $40 \mu \mathrm{M}$ oxidized cytochrome $c$. The activity was measured for 5 minutes.

Measurement of ubiquinol cytochrome c reductase (QCCR): Complex III activity

The assay involved oxidized cytochrome $c$ as the electron acceptor and decylubiquinol as donor. The enzymatic reaction was performed in $10 \mathrm{mM} \mathrm{KH}_{2} \mathrm{PO}_{4}(\mathrm{pH} 7.8), 2 \mathrm{mM}$ EDTA and $1 \mathrm{mg} / \mathrm{ml}$ BSA with mitochondria (20 to $40 \mu \mathrm{g}$ of protein), $80 \mathrm{mM}$ decylubiquinol (donor), $240 \mu \mathrm{M} \mathrm{KCN}, 4 \mu \mathrm{M}$ rotenone, and $200 \mu \mathrm{M}$ ATP. The reaction was started by adding $40 \mu \mathrm{M}$ oxidized cytochrome $c$. The activity was measured for 5 minutes. Added $0.4 \mu \mathrm{M}$ antimycin A to distinguish between the reduction of cytochrome $c$ catalyzed by complex III and the non-enzymatic reduction of cytochrome $c$ by the reduced quinone

Measurement of cytochrome c oxidase: Complex IV activity

Mitochondria (5 to $20 \mu \mathrm{g}$ of protein) was added to $1 \mathrm{ml}$ of $10 \mathrm{mM} \mathrm{KH}_{2} \mathrm{PO}_{4}$ (pH 6.5), $0.25 \mathrm{M}$ sucrose and $1 \mathrm{mg} / \mathrm{ml} \mathrm{BSA}$. The reaction was started by the addition of $10 \mu \mathrm{M}$ reduced cytochrome $c$. The decreased absorbance at $550 \mathrm{~nm}$ for 3 minutes was measured. The reaction was inhibited with $240 \mu \mathrm{M} \mathrm{KCN}$ and monitored the absorbance at $550 \mathrm{~nm}$ for an additional 2 minutes.

Measurement of complex V (oligomycin sensitive $\mathrm{Mg}^{++}$ATPase) activity

Complex V activity (ATP hydrolysis) was measured spectrophotometrically by a coupled assay using lactate dehydrogenase and pyruvate kinase as the coupling enzyme. Reaction medium containing $200 \mu \mathrm{l}$ of $50 \mathrm{mM}$ Tris $\mathrm{HCl}, \mathrm{pH} 8.0,5 \mathrm{mg} / \mathrm{ml} \mathrm{BSA}, 20 \mathrm{mM} \mathrm{MgCl}_{2}, 50 \mathrm{mM} \mathrm{KCl}, 15 \mu \mathrm{M}$ Carbonyl cyanide m-chlorophenyl hydrazone, $5 \mu \mathrm{M}$ antimycin A, $10 \mathrm{mM}$ phosphoenolpyruvate, $2.5 \mathrm{mM}$ ATP, $4 \mathrm{U}$ lactate dehydrogenase, pyruvate kinase, and $1 \mathrm{mM}$ NADH were prepared and incubated for 5 minutes at $37^{\circ} \mathrm{C}$. Reaction was followed at 340 $\mathrm{nm}$ for 3 minutes after adding mitochondria ( 20 to $40 \mu \mathrm{g}$ of protein) to the reaction mixture. $3 \mu \mathrm{M}$ oligomycin was added and followed the reaction for an additional 3 minutes to distinguish the ATPase activity coupled to the respiratory chain. 


\section{Cellular Physiology $\quad$ Cell Physiol Biochem 2012;30:83-94 \\ \begin{tabular}{l|l}
\hline DOI: $10.1159 / 000339043$ & C 2012 S. Karger AG, Basel
\end{tabular} \\ and BiOchemistry Published online: June 08, $2012 \quad$ www.karger.com/cpb \\ Kurian/Berenshtein/Saada/Chevion: Mitochondrial Subpopulation and Cardiac Ischemia Reperfusion Injury}

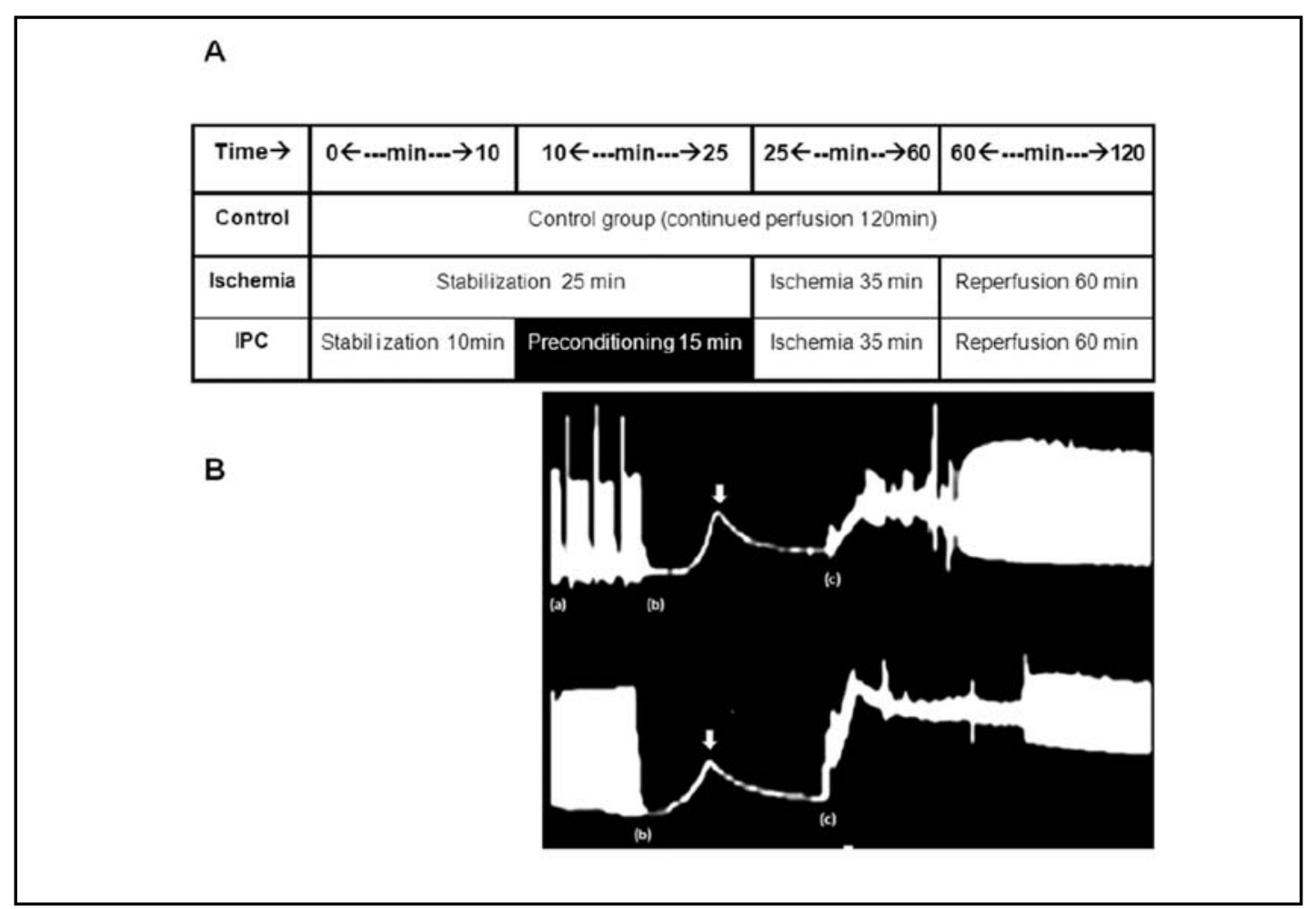

Fig. 1. A: Scheme of experiments; and B: Typical left ventricle pressure trace (mm $\mathrm{Hg}$ ) of ischemia and reperfused heart. (a) denotes the onset of ischemia preconditioning ( 3 cycles of 2 minutes ischemia followed by 3 minutes reperfusion). (b) and (c) denote onset of ischemia and reperfusion respectively and arrow represents ischemic hypercontracture.

Measurement of cytochrome $a+a 3, b$

The concentration of mitochondrial cytochromes $c+c 1, b$ and $a+a 3$ were determined from the difference spectra recorded with double beam dual wavelength spectrophotometer. $20 \mu$ of mitochondrial suspension was added to $1 \mathrm{ml}$ of $20 \mathrm{~mm}$ Tris buffer, $\mathrm{pH} 7.2$ and the oxidized spectra were recorded from $500 \mathrm{~nm}$ to $650 \mathrm{~nm}$. Reduced spectra were recorded in the same sample after reduction of the cytochromes with sold sodium dithionite. The concentrations of the cytochromes were calculated from the Gaussian deconvolution of the reduced minus oxidized different spectra using the extinction coefficient: eb (561-572) $=20 \mathrm{mM}^{-1} \mathrm{~cm}^{-1}$, ea+a3 $(605-630)=24 \mathrm{mM}^{-1} \mathrm{~cm}^{-1}$

\section{Statistical data analysis}

The comparison between values of the same group, at various time points along the experiment was conducted using Student's t-test or ANOVA. Differences in variables between groups for a specific time point were analyzed using one-way ANOVA. Values of $\mathrm{P}<0.05$ were considered significant.

\section{Results}

Rat hearts were subjected to the different experimental procedures as described in the materials and methods. SSM and IFM were isolated and analyzed for OXPHOS function.

\section{Cardiac hemodynamic findings}

Cardiac functional damage caused by ischemia and reperfusion is shown in Fig. 1. The sample trace of left ventricle pressure shows the development of hyper-contracture during ischemia (arrow). Following reperfusion, increased end diastolic pressure, decreased peak 


\section{Cellular Physiology Cell Physiol Biochem 2012;30:83-94

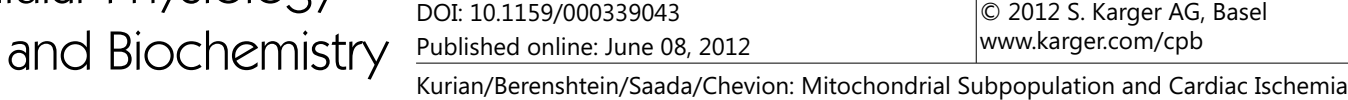 Kurian/Berenshtein/S
Reperfusion Injury}

Fig. 2. Measurement of mitochondrial respiration in glutamate-malate (GM) medium and succinate medium. (A) ADP/O ratio in GM medium (B) ADP/O ratio in succinate medium (C) Respiratory control ratioinGMmedium. Results are expressed as mean \pm SD of $n=4-6$ independent assays. $\quad\left({ }^{*}\right) \quad \mathrm{p}<0.05$, statistically different from respective controls (P25vs IPC; P60vs I, IPC+ I; P120vs I/R, IPC+IR. (\#) $\mathrm{p}<0.05$, statistically different between the sub populations.

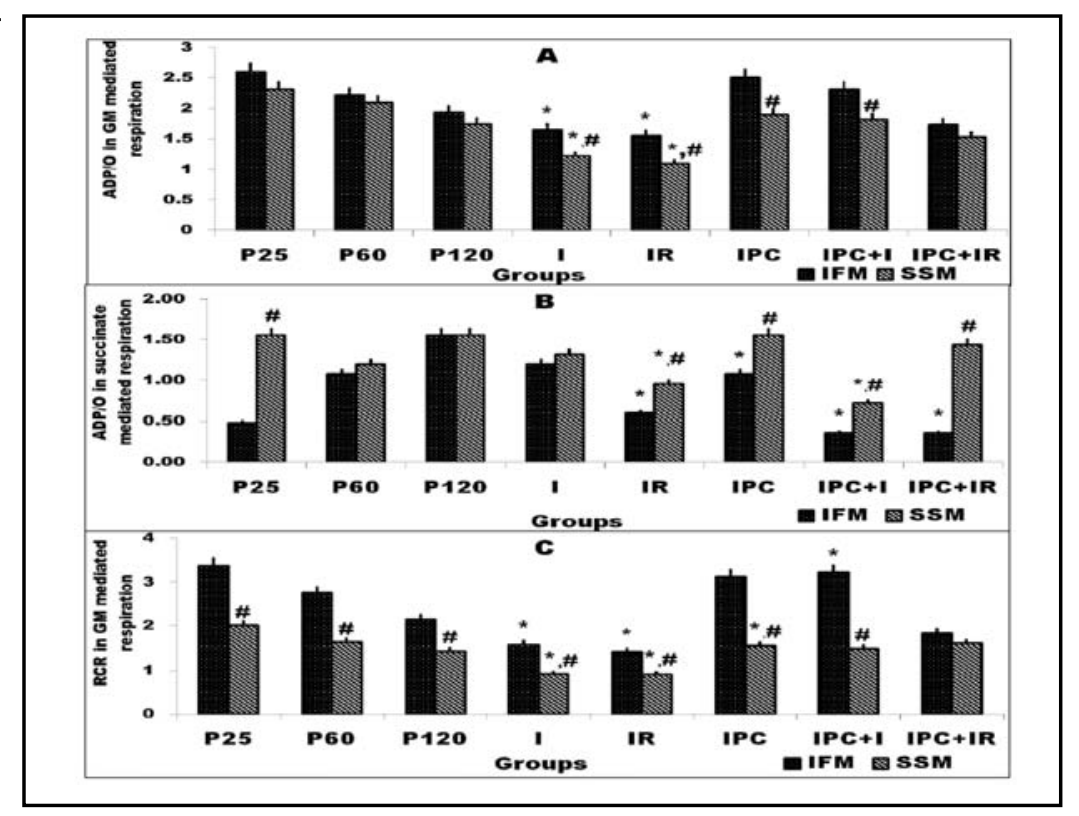

systolic pressure and developed pressure was observed. Elevated end diastolic stiffness has been correlated to mitochondrial dysfunction [16] Myocardial I/R is known to induce mitochondrial dysfunction, particularly in terms of OXPHOS [17],preconditioning the heart increased the end developed pressure.

Effect of ischemia, reperfusion and ischemic preconditioning on mitochondrial oxidative phosphorylation capacity

I/R markedly decreased ADP/O in both IFM and SSM with glutamate plus malate as substrate. Notably SSM showed further decline of $20 \%$ as compared to IFM (Fig. 2a). With succinate as substrate, a similar decrease in ADP/O was observed in both subpopulations. But, IFM showed further decline of $15 \%$ (Fig. 2b) compared to SSM, in succinate mediated respiration. IPC improved the ADP/O in both IFM and SSM with glutamate plus malate as substrate but not with succinate as substrate, instead only SSM showed improvement in succinate mediated respiration. Declined respiratory control ratio in both IFM and SSM during ischemia and reperfusion with glutamate plus malate as substrate, indicated loosely coupled oxidative phosphorylation (Fig. 2c), but no difference between the sub-populations were observed.

The activity of mitochondrial electron transport chain complexes

Damage to complex I leading to decreased NQR activity during ischemia and reperfusion were documented earlier $[4,18]$ To further assess the variability of damage to complex I in different subpopulation of mitochondria, we compared the effect of ischemia and reperfusion on NQR activity in IFM and SSM respectively. During ischemia, NQR activity was normal, like in the control, in IFM, but found to be declined in SSM by $20 \%$. On the other hand, reperfusion induced $10 \%$ and $30 \%$ decrease in NQR activity in IFM and SSM, respectively, compared to controls (Fig. 3a). Compared to IFM, SSM showed 20\% decrease in NQR activity during ischemia and around 18\% decline in activity during reperfusion (Fig. 3a). Rotenone sensitive NCCR measuring complex I+III activity did not show any significant difference in NCCR activity between IFM and SSM, irrespective of ischemia or reperfusion (Fig. 3b). The second respiratory chain complex enzyme, $\mathrm{SQR}$ is involved in the metabolism as part of the citric acid cycle and of the aerobic respiratory chain, one of the enzymes that govern the flow of electrons in ETC, showed decreased activity during ischemia but not in reperfusion [19]. During ischemia, SQR activity was found to be lowered by $20 \%$ in both sub-populations, but subsequent reperfusion improved the activity in SSM to near normal level, while the activity 


\section{Cellular Physiology Cell Physiol Biochem 2012;30:83-94 \\ \begin{tabular}{ll|l} 
and BiOChemistry & $\begin{array}{l}\text { DOI: 10.1159/000339043 } \\
\text { Published online: June 08, } 2012\end{array}$ & $\begin{array}{l}\text { C 2012 S. Karger AG, Basel } \\
\text { www.karger.com/cpb }\end{array}$ \\
\cline { 2 - 3 } & Kurian/Berenshtein/Saada/Chevion: Mitochondrial Subpopulation and Cardiac Ischemia
\end{tabular} Kurian/Berenshtein/S
Reperfusion Injury}

Fig. 3. Mitochondrial enzyme activities (A) Rotenone sensitive NADH decylubiquinone oxidoreductase (NQR). (B) Rotenone sensitive NADH cytochrome c oxidoreductase activity (NCCR). Succinate decyl ubiquinone DCPIP reductase (SQR). (D) Succinate cytochrome c reductase (SCCR). Activity is expressed as $\mu \mathrm{M}$ of $\mathrm{NADH} \quad$ oxidized $/ \mathrm{min} / \mathrm{mg}$ protein for $\mathrm{NQR}, \mu \mathrm{M}$ of cytochrome c reduced / min / mg protein for NCCR; $\mu \mathrm{M}$ of DCPIP reduced / $\mathrm{min} / \mathrm{mg}$ protein for SQR and $\mu \mathrm{M}$ of cytochrome c reduced / $\mathrm{min}$ / mg protein for SCCR. Results are expressed as mean \pm SD of $n=4-6$ independent assays: $\left(^{*}\right) \quad \mathrm{p}<0.05, \quad$ statistically different from respective controls (P25vs IPC; P60vs I, IPC+ I; P120vs I/R, IPC+IR. (\#) $\mathrm{p}<0.05, \quad$ statistically different between the sub populations.

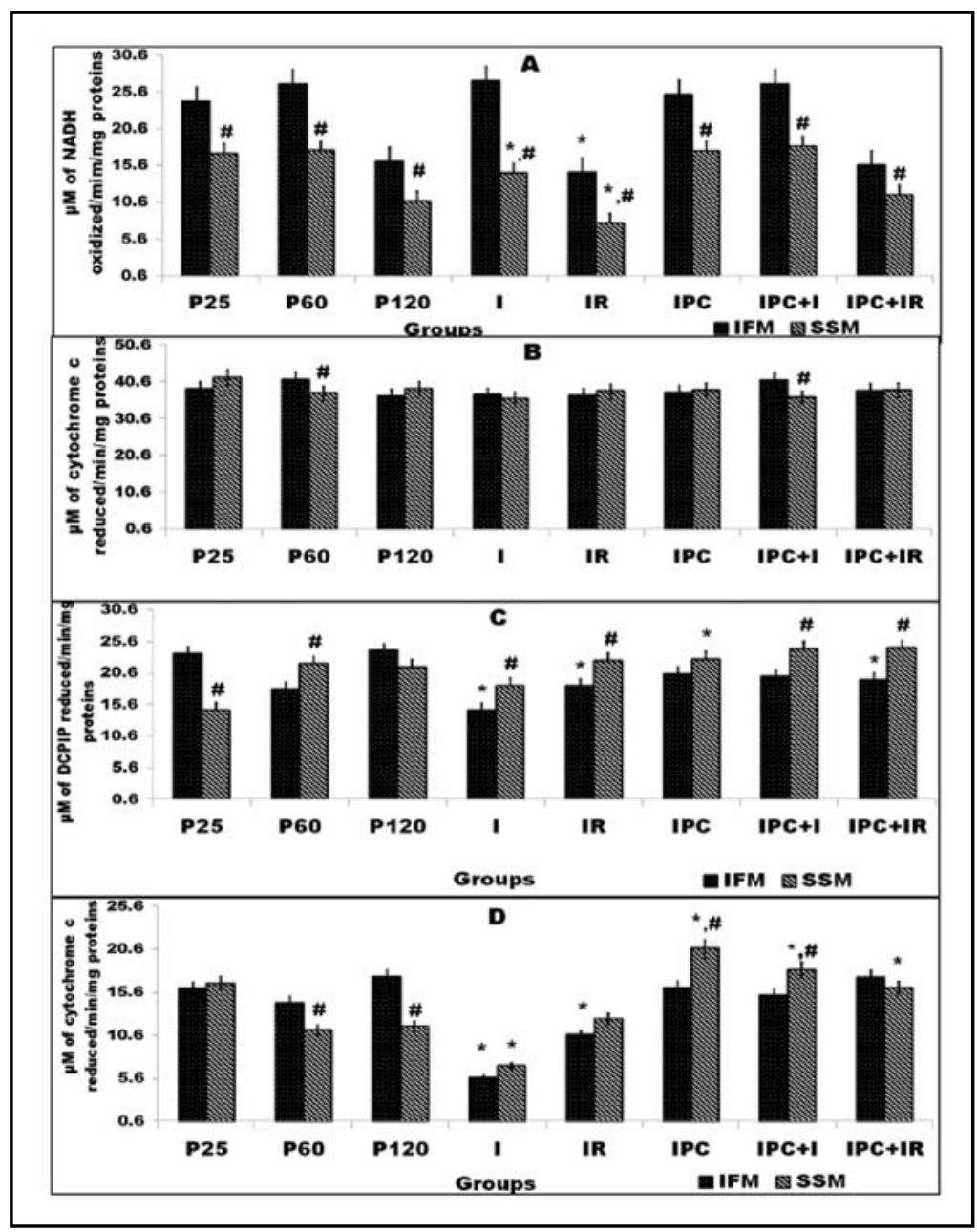

in IFM remained low. Compared to IFM, SSM showed 25\% increased SQR activity during reperfusion (Fig. 3c). SCCR, measuring of complex II+III, showed a significantly decreased activity in both IFM (60\%) and SSM (40\%) during ischemia, but upon reperfusion, both subpopulations showed an improved activity. On comparison between the sub-populations, SSM showed a significant increase in SCCR activity as compared to IFM during ischemia (37\%) and reperfusion (43\%) (Fig. 3d). Thus the activities of NQR and NCCR versus SQR and SCCR indicate that during ischemia and reperfusion IFM preferably utilize NADH and SSM favor $\mathrm{FADH}_{2}$ as the source of reducing equivalents for electron transfer. The cytochrome bc1 complex or complex III, QCCR represents a confluence point for reducing equivalents from the various dehydrogenase, transferring electrons from hydroquinones (ubiquinol, reduced $\mathrm{CoQ}$ ) to cytochrome $\mathrm{c}$ with concomitant translocation of protons across the membrane [20] QCCR showed declined activity in both sub-populations but did not show any significant change between them during ischemia or reperfusion (Fig. 4a). In accord with complex III activity, there was no distinct difference between the concentrations of cytochrome b, predominantly present in complex III. In fact cytochrome b levels were lower in both IFM and SSM during reperfusion (Fig. 4b). Complex IV, which catalyzes the complete reduction of dioxygen to water and promote proton translocation across the mitochondrial membrane was reported to be adversely affected during ischemia and reperfusion [21] We could not find significant difference between IFM and SSM (Fig. 4c) even though both sub-populations showed declined activity during ischemia and reperfusion. Similarly, the content of cytochrome $\mathrm{aa}_{3}$ (mainly present in COX) was not significantly different in both IFM and SSM, during ischemia and even in reperfusion (Fig. 4d), but was found to be decreased compared to controls. The activity of complex V (oligomycin-sensitive ATPase) was found to be low in 


\section{Cellular Physiology and Biochemistry}

Cell Physiol Biochem 2012;30:83-94

\begin{tabular}{l|l}
\hline DOI: $10.1159 / 000339043$ & C 2012 S. Karger AG, Basel
\end{tabular}

Published online: June 08, 2012

www.karger.com/cpb

Kurian/Berenshtein/Saada/Chevion: Mitochondrial Subpopulation and Cardiac Ischemia Reperfusion Injury

Fig. 4. Mitochondrial enzyme activities and level of cytochromes. (A) Ubiquinone cytochrome c reductase (QCCR). (B) cytochrome b level. (C) cytochrome c oxidase (COX). (D) cytochrome a+a3 level. Activity is expressed as $\mu \mathrm{M}$ of cytochrome $\mathrm{c}$ reduced per min per mg protein for QCCR; $\mu$ Mper mg protein for cytochrome $\mathrm{b} ; \mu \mathrm{M}$ of cytochrome c oxidized per min per mg protein for COX and ìM per mg protein for cytochrome aa3. Results are expressed as mean \pm SD of $n=4-6$ independent assays. $\left({ }^{*}\right) \mathrm{p}<0.05$, statistically different from respective controls (P25vs IPC; P60vs I, IPC+ I; P120vs I/R, IPC+IR. (\#) $p<0.05$, statistically different between the sub populations.

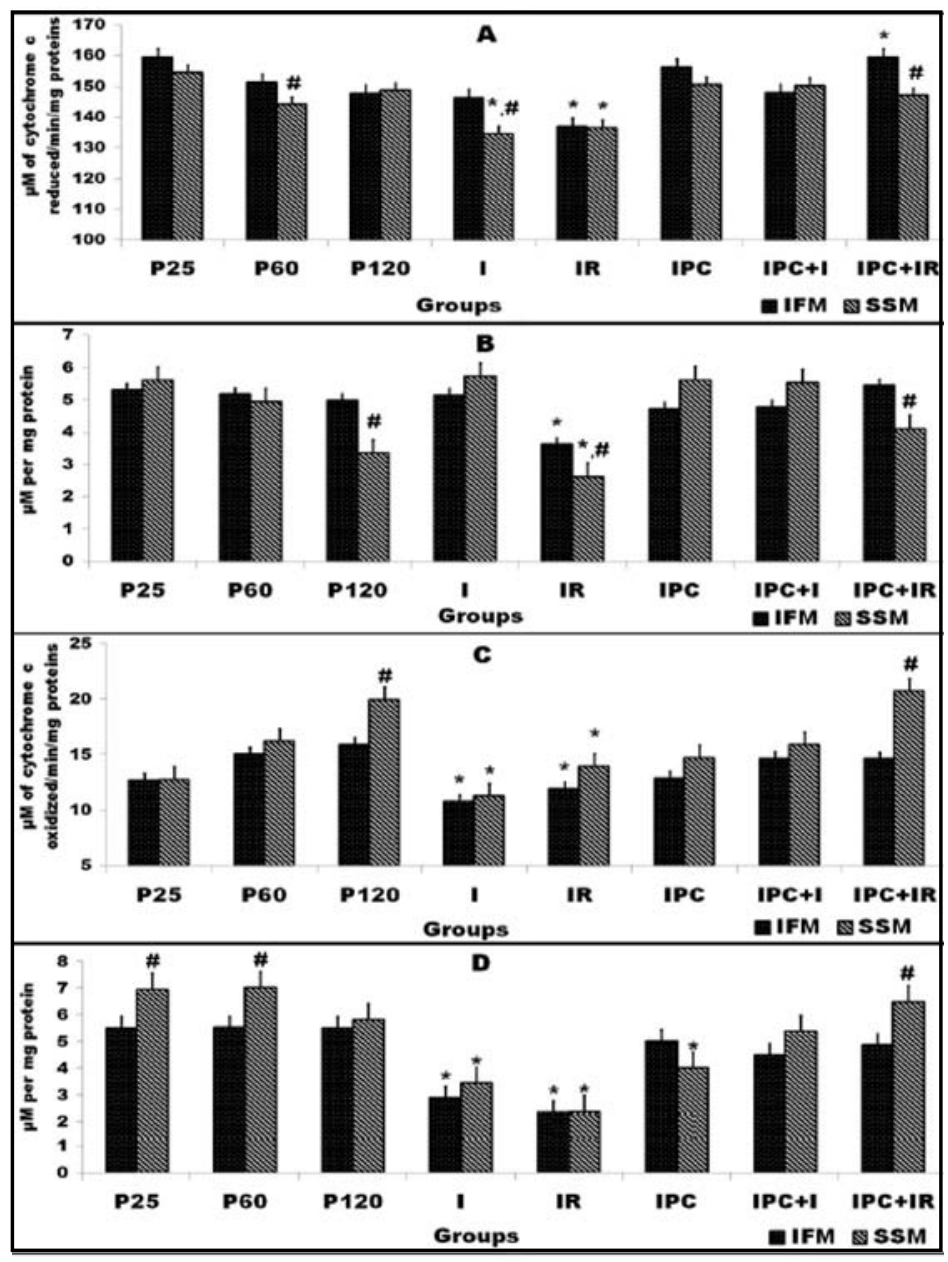

Fig. 5. Activity of F0F1 Atpase. Activity is expressed as $\mu \mathrm{M}$ of NADH oxidized/min/mg protein. Results are expressed as mean \pm SD of n=4-6 independent assays. $\left.{ }^{*}\right) \mathrm{p}<0.05$, statistically different from respective controls (P25vs IPC; P60vs I, IPC+ I; P120vs I/R, IPC+IR. (\#) $\mathrm{p}<0.05$, statistically different between the sub populations.

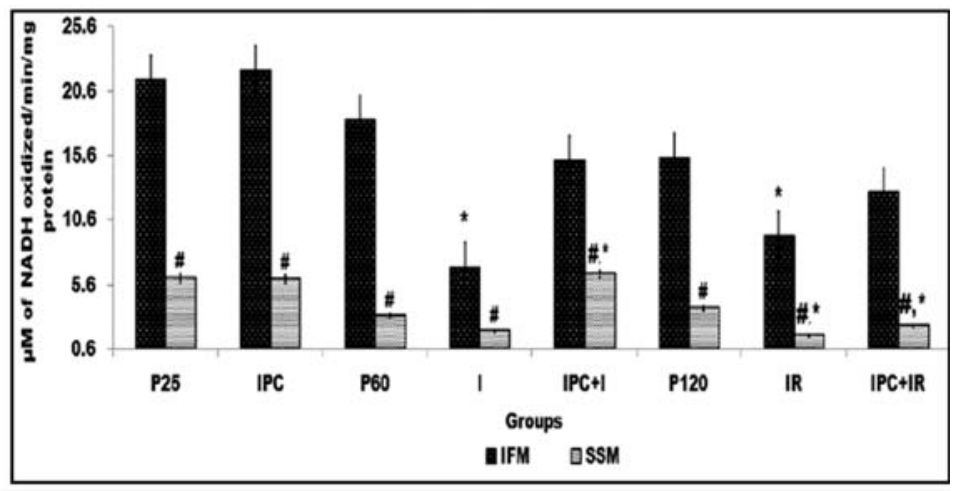

both sub-populations during ischemia and reperfusion. Nevertheless, compared to IFM, the decreased activity in SSM during ischemia (24\%) and reperfusion (26\%) (Fig. 5a) underline the distinct enzymatic behavior in two sub-populations of mitochondria.

To examine the extent of IPC-protection of IFM and SSM by IPC prior to I/R we examined the ETC enzymes in both sub-populations. Complex I activity was preserved in both IFM and SSM upon IPC alone (Fig. 3a). However, applying the IPC procedure prior to either ischemia or reperfusion resulted in an improved protection in SSM against ischemic injury (31\% recovery) and reperfusion injury (10\% recovery). On the other hand, SQR activity improved by $36 \%$ in IFM and 33\% in SSM during ischemia but only 5\% in IFM and $10 \%$ in SSM during reperfusion (Fig. 3c). Similarly, SCCR also showed significant preservation of its activity to 


\section{Cellular Physiology Cell Physiol Biochem 2012;30:83-94 \\ \begin{tabular}{ll|l} 
and Biochemistry & $\begin{array}{l}\text { DOI: 10.1159/000339043 } \\
\text { Published online: June 08, } 2012\end{array}$ & $\begin{array}{l}\text { × } 2012 \text { S. Karger AG, Basel } \\
\text { www.karger.com/cpb }\end{array}$ \\
\cline { 2 - 3 } Kurian/Berenshtein/Saada/Chevion: Mitochondrial Subpopulation and Cardiac Ischemia
\end{tabular} Kurian/Berenshtein/S
Reperfusion Injury}

over $100 \%$ in both IFM and SSM during ischemia and 62\% in IFM and 29\% in SSM during reperfusion (Fig. 3d). Irrespective of the preference in reducing equivalent in both SSM and IFM during ischemia and reperfusion, IPC treatment maintained the activities of proximal ETC enzymes to control levels. In the ischemic heart, IPC preserved the activities of distal electron transport chain enzymes like COX and F0F1 ATPase in IFM around 36\% and 34\% respectively, and in SSM around $42 \%$ and more than $100 \%$ respectively (Fig. 4c, 5). Similarly, IPC pre-treatment of the reperfused heart improved COX and F0F1 ATPase activity in IFM by $23 \%$ and $68 \%$ respectively, against $49 \%$ and $43 \%$ respectively, in SSM (Fig. 4c, 5). Barring complex II activity, SSM suffered a major ischemia-associated decreased enzyme activity, which recovered markedly to near control level by preconditioning.

\section{Discussion}

The main findings of this study are as follows: i) Functional ETC enzyme activities and respiration efficiency of the mitochondrial sub-populations - IFM and SSM - have different vulnerability towards ischemia and reperfusion. ii) During ischemia and reperfusion, IFM and SSM showed distinct preference to reducing equivalent as the source of electron to ETC: IFM utilized more NADH while SSM used more FADH $_{2}$ as the main source for reducing equivalent. iii) Preconditioning preserved the functional activity of respiratory enzymes in ETC of both IFM and SSM.

Many studies have reported damage to the mitochondrial oxidative phosphorylation machinery in ischemia and reperfusion and associated pathologies [22, 23]. However, in most of these mitochondrial sub-populations were not taken into account. Cardiac mitochondria exist in two functionally distinct populations: SSM residing beneath the plasma membrane and IFM, located between the myofibrils. These were reported to be affected differently in aging and in cardiomyopathy [24, 25]. These sub-populations are also expected to be distinctly affected during reperfusion and preconditioning. A recent study in aged rats have shown that mitochondria suffered major damage to complex III and IV during ischemia rather than reperfusion, in both IFM and SSM; the effect of IPC was not evaluated [26]. Similarly, another study by Duan and Karmazyn, explained that reperfusion caused major damage to rat heart [27]. In contrast, ischemia of rabbit heart did not result in a reduction of oxidative phosphorylation [28]. In our study, NCCR, SQR, SCCR were found to be decreased during ischemia while NQR, QCCR and F0F1 ATPase activities were lowered during reperfusion. Similarly, cytochromes $\mathrm{b}$ and $\mathrm{aa}_{3}$ were also low during reperfusion. According to our data, the impact of ischemia or I/R to the mitochondrial sub-populations varied. The ETC enzyme activities of subpopulations were affected similar in both ischemia and reperfusion, but the magnitudes of changes were different and were more severe on ischemic insult. Notably the ATP production mediated by F0F1 ATPase activity, a non redox complex, reperfusion induces more damage than ischemia.

Based on our result, in general, the reperfusion phase affected the proximal part of the ETC rather more severely and distinctly in both sub populations. This is exemplified by comparing the activity of both sub-populations, during reperfusion, where complex I activity was significantly decreased mainly in SSM (Fig. 3a) and in contrast, complex II activity was significantly lowered only in IFM. Additionally, mitochondrial respiration measured with glutamate plus malate was more effective in IFM (Fig. 2a) while SSM performed better with succinate (Fig. 2), underlining these findings. These results emphasize distinct changes in ETC enzymatic behavior in SSM and IFM, upon ischemia and reperfusion. With respect to the distal part of the ETC both ischemia and reperfusion caused similar damage to both IFM and SSM.

In our study both ischemia and reperfusion severely affected the activity of complex $\mathrm{V}$ and IV (distal part of ETC) in both IFM and SSM. Moreover, mitochondrial respiration function measured by ADP/O supported the declined activity of complex V. Apparently, the electron flow of ETC, measured by COX activity (terminal redox complex in ETC) were the same in both SSM and IFM, despite the insult caused by the ischemia and the reperfusion, 


\section{Cellular Physiology Cell Physiol Biochem 2012;30:83-94 \\ \begin{tabular}{ll|l} 
and Biochemistry & $\begin{array}{l}\text { DOI: 10.1159/000339043 } \\
\text { Published online: June 08, } 2012\end{array}$ & $\begin{array}{l}\text { × } 2012 \text { S. Karger AG, Basel } \\
\text { www.karger.com/cpb }\end{array}$ \\
\cline { 2 - 3 } Kurian/Berenshtein/Saada/Chevion: Mitochondrial Subpopulation and Cardiac Ischemia
\end{tabular} Kurian/Berenshtei}

but had distinct ATP production (Fig. 2a, c) as measured by ADP/O and complex V activity (non redox complex), indicating the importance of the uncoupling effect in pathology. In agreement, RCR data (Fig. 2b) also support the uncoupling during ischemia and reperfusion on both IFM and SSM. These suggest that both IFM and SSM functions were affected similarly by the ischemic insult. The decreased ADP/O and RCR (Fig. 2) in SSM during I/R may not be due to additional injury, but rather by the influence of $\mathrm{FADH}_{2}$ as predominant reducing equivalent, which can provide less ATP than NADH. Oxidative phosphorylation yield is higher when NADH is the electron donor (three coupling sites: complex 1, III and IV), as compared to $\mathrm{FADH}_{2}$ (two coupling sites: complex III and IV). Previously, it has been reported that $\mathrm{FADH}_{2}$ derived from fatty acid metabolism can promote mitochondrial uncoupling [29]. Moreover, the impaired oxidative phosphorylation after cardiac ischemia and reperfusion injury can be reversed upon post ischemic administration of succinate [30].

The selective preference for reducing equivalents, by the sub-populations, may be due to their distinct localizations, and to certain extent, to their prime functions [14]. SSM, being predominantly situated beneath the plasma membrane is influenced by the myocardium that has remarkable ability to switch between the utilization of carbohydrate and fat as a fuel source, so that ATP production is maintained at a constant rate in the face of diverse physiological and dietary conditions [31] On the contrary, IFM buried deep inside the myofibrils, mainly produce ATP for myocardial contractility [32].

IPC, involving exposing the heart to brief periods of ischemia interspersed with periods of normal perfusion, prior to the prolonged ischemia, rendered protection towards reperfusion injury [33]. In our study, both IFM and SSM preserved their functional ETC enzyme activities upon IPC when followed by prolonged ischemia and reperfusion. Notably; the enzyme activities in SSM were more intact. This may be due to the fact that IFM were less affected by ischemia and reperfusion, especially the proximal part of ETC compared to SSM. The IPC procedure alone insignificantly affect the enzyme activities of ETC, in both IFM and SSM, except for SQR and SCCR, indicating the influence of complex II in the IPC-mediated mitochondrial protection. The ratio of NADH oxidation versus $\mathrm{FADH}_{2}$ oxidation depends on proton motive force, and lowering proton motive force by uncoupling favors $\mathrm{FADH}_{2}$ oxidation, i.e. lipids versus carbohydrate utilization [34] Indeed, this was observed during IPC (Fig. 3), that utilizes $\mathrm{FADH}_{2}$ by activating complex II and can render cardio protection through ROS that may involve in the inhibition of the opening of the MPTP, a key player of cell death by ischemia reperfusion injury [35]. Moreover, complex II plays an important role in replenishment of ubiqinone pool, where the latter not only fine tune the mitochondrial functional activities but also can impart significant influence on the overall cardiac recovery from I/R [36]. In short, mitochondria are similar in their central role in cellular function, the sub populations are differently influenced by pathological states especially I/R (in this study). Recent finding on the co-existence of heterogeneously damaged mitochondria within the same cell subjected to hyper-contracture [37], pathological hallmark of reperfusion induced injury, emphasizes the quantity and quality of mitochondrial sub populations required for normal cellular physiological functions. Ischemic preconditioning mechanism probably improves either quantity or quality of mitochondrial sub populations (more studies are required). Based on our observations we conclude that the cardiac mitochondrial subpopulations like IFM and SSM behave differently to myocardial insult such as ischemia and reperfusion: mitochondrial dysfunction, one of the prime targets of most of cardiac pathophysiology, need to be evaluated by considering both fractions in weighted combination and separately.

\section{Acknowledgements}

Lady Davis foundation is acknowledged for their financial support to GAK. Mottie Chevion is the incumbent of the Dr. William Ganz Chair of Heart Studies at the Hebrew University of Jerusalem. This study was supported by grants from the Pepka and Dr. Moshe Bergman Memorial Fund, Joels Landovsky Fund (Hebrew University) and German Israeli Fund (GIF). 


\section{Cellular Physiology Cell Physiol Biochem 2012;30:83-94 \begin{tabular}{l|l}
\hline DOI: $10.1159 / 000339043$ & C 2012 S. Karger AG, Basel
\end{tabular} and Biochemistry \\ Kurian/Berenshtein/Saada/Chevion: Mitochondrial Subpopulation and Cardiac Ischemia Reperfusion Injury}

\section{References}

1 Boengler K, Hilfiker-Kleiner D, Heusch G, Schulz R: Inhibition of permeability transition pore opening by mitochondrial stat3 and its role in myocardial ischemia/reperfusion. Basic Res Cardiol 2010;105:771-785.

2 Chen Q Lesnefsky EJ: Blockade of electron transport during ischemia preserves bcl-2 and inhibits opening of the mitochondrial permeability transition pore. FEBS Lett 2011;585:921-926.

3 Lesnefsky EJ, Chen Q, Slabe TJ, Stoll MS, Minkler PE, Hassan MO, Tandler B, Hoppel CL: Ischemia, rather than reperfusion, inhibits respiration through cytochrome oxidase in the isolated, perfused rabbit heart: Role of cardiolipin. Am J Physiol Heart Circ Physiol 2004;287:H258-267.

4 Rouslin W, Ranganathan S: Impaired function of mitochondrial electron transfer complex i in canine myocardial ischemia: Loss of flavin mononucleotide. J Mol Cell Cardiol 1983;15:537-542.

5 Paradies G, Petrosillo G, Pistolese M, Di Venosa N, Federici A, Ruggiero FM: Decrease in mitochondrial complex i activity in ischemic/reperfused rat heart: Involvement of reactive oxygen species and cardiolipin. Circ Res 2004;94:53-59.

6 Tanno M, Miura T: Adenine nucleotide translocator, a mitochondrial carrier protein, and fate of cardiomyocytes after ischaemia/reperfusion. Cardiovasc Res 2008;80:1-2.

7 Petrosillo G, Ruggiero FM, Di Venosa N, Paradies G: Decreased complex iii activity in mitochondria isolated from rat heart subjected to ischemia and reperfusion: Role of reactive oxygen species and cardiolipin. FASEB J 2003;17:714-716.

8 Chen Q Yin G, Stewart S, Hu Y, Lesnefsky EJ: Isolating the segment of the mitochondrial electron transport chain responsible for mitochondrial damage during cardiac ischemia. Biochem Biophys Res Commun 2010;397:656-660.

9 Sako EY, Kingsley-Hickman PB, From AH, Foker JE, Ugurbil K: Atp synthesis kinetics and mitochondrial function in the postischemic myocardium as studied by 31p nmr. J Biol Chem 1988;263:10600-10607.

10 Hardy L, Clark JB, Darley-Usmar VM, Smith DR, Stone D: Reoxygenation-dependent decrease in mitochondrial nadh:Coq reductase (complex i) activity in the hypoxic/reoxygenated rat heart. Biochem J 1991;274:133-137.

11 Kuznetsov AV, Margreiter R: Heterogeneity of mitochondria and mitochondrial function within cells as another level of mitochondrial complexity. Int J Mol Sci 2009;10:1911-1929.

12 Powers SK, Murlasits Z, Wu M, Kavazis AN: Ischemia-reperfusion-induced cardiac injury: A brief review. Med Sci Sports Exerc 2007;39:1529-1536.

13 Chevion M, Jiang Y, Har-El R, Berenshtein E, Uretzky G, Kitrossky N: Copper and iron are mobilized following myocardial ischemia: Possible predictive criteria for tissue injury. Proc Natl Acad Sci U S A 1993;90:1102-1106.

14 Palmer JW, Tandler B, Hoppel CL: Biochemical properties of subsarcolemmal and interfibrillar mitochondria isolated from rat cardiac muscle. J Biol Chem 1977;252:8731-8739.

15 Barrientos A, Fontanesi F, Diaz F: Evaluation of the mitochondrial respiratory chain and oxidative phosphorylation system using polarography and spectrophotometric enzyme assays. Curr Protoc Hum Genet 2009;Chapter 19:Unit19 13.

16 Kapelko VI, Veksler VI, Popovich MI, Ventura-Clapier R: Energy-linked functional alterations in experimental cardiomyopathies. Am J Physiol 1991;261:39-44.

17 Duan JM, Karmazyn M: Effect of d,l-carnitine on the response of the isolated heart of the rat to ischaemia and reperfusion: Relation to mitochondrial function. Br J Pharmacol 1989;98:1319-1327.

18 Veitch K, Hombroeckx A, Caucheteux D, Pouleur H, Hue L: Global ischaemia induces a biphasic response of the mitochondrial respiratory chain. Anoxic pre-perfusion protects against ischaemic damage. Biochem J 1992;281:709-715.

19 Scheffler IE: Molecular genetics of succinate:Quinone oxidoreductase in eukaryotes. Prog Nucleic Acid Res Mol Biol 1998;60:267-315.

20 Lenaz G, Genova ML: Structure and organization of mitochondrial respiratory complexes: A new understanding of an old subject. Antioxid Redox Signal;12:961-1008.

21 Slatter MA, Angus B, Windebank K, Taylor A, Meaney C, Lester T, Norbury G, Hambleton S, Abinun M, Flood TJ, Cant AJ, Gennery AR: Polymorphous lymphoproliferative disorder with hodgkin-like features in common gamma-chain-deficient severe combined immunodeficiency. J Allergy Clin Immunol 2011;127:533-535. 


\section{Cellular Physiology Cell Physiol Biochem 2012;30:83-94 \\ \begin{tabular}{ll|l} 
and BiOChemistry & $\begin{array}{l}\text { DOI: 10.1159/000339043 } \\
\text { Published online: June 08, } 2012\end{array}$ & $\begin{array}{l}\text { C 2012 S. Karger AG, Basel } \\
\text { www.karger.com/cpb }\end{array}$ \\
\cline { 2 - 3 } \\
$\begin{array}{l}\text { Kurian/Berenshtein/Saada/Chevion: Mitochondrial Subpopulation and Cardiac Ischemia } \\
\text { Reperfusion Injury }\end{array}$
\end{tabular}}

22 Sack MN: Mitochondrial depolarization and the role of uncoupling proteins in ischemia tolerance. Cardiovasc Res 2006;72:210-219.

23 Tompkins AJ, Burwell LS, Digerness SB, Zaragoza C, Holman WL, Brookes PS: Mitochondrial dysfunction in cardiac ischemia-reperfusion injury: Ros from complex i, without inhibition. Biochim Biophys Acta 2006;1762:223-231.

24 Dabkowski ER, Williamson CL, Bukowski VC, Chapman RS, Leonard SS, Peer CJ, Callery PS, Hollander JM: Diabetic cardiomyopathy-associated dysfunction in spatially distinct mitochondrial subpopulations. Am J Physiol Heart Circ Physiol 2009;296:H359-369.

25 Judge S, Leeuwenburgh C: Cardiac mitochondrial bioenergetics, oxidative stress, and aging. Am J Physiol Cell Physiol 2007;292:C1983-1992.

26 Chen Q Moghaddas S, Hoppel CL, Lesnefsky EJ: Ischemic defects in the electron transport chain increase the production of reactive oxygen species from isolated rat heart mitochondria. Am J Physiol Cell Physiol 2008;294:C460-466.

27 Duan J, Karmazyn M: Protective effects of amiloride on the ischemic reperfused rat heart. Relation to mitochondrial function. Eur J Pharmacol 1992;210:149-157.

28 Flameng W, Andres J, Ferdinande P, Mattheussen M, Van Belle H: Mitochondrial function in myocardial stunning. J Mol Cell Cardiol 1991;23:1-11.

29 Maassen JA, Romijn JA, Heine RJ: Fatty acid-induced mitochondrial uncoupling in adipocytes as a key protective factor against insulin resistance and beta cell dysfunction: A new concept in the pathogenesis of obesity-associated type 2 diabetes mellitus. Diabetologia 2007;50:2036-2041.

30 Cairns CB, Ferroggiaro AA, Walther JM, Harken AH, Banerjee A: Postischemic administration of succinate reverses the impairment of oxidative phosphorylation after cardiac ischemia and reperfusion injury. Circulation 1997;96:II-260-265.

31 Rosca MG, Hoppel CL: Mitochondria in heart failure. Cardiovasc Res 2010;88:40-50.

32 Hoppel CL, Tandler B, Fujioka H, Riva A: Dynamic organization of mitochondria in human heart and in myocardial disease. Int J Biochem Cell Biol 2009;41:1949-1956.

33 Rodrigo GC, Samani NJ: Ischemic preconditioning of the whole heart confers protection on subsequently isolated ventricular myocytes. Am J Physiol Heart Circ Physiol 2008;294:H524-531.

34 Leverve X, Batandier C, Fontaine E: Choosing the right substrate. Novartis Found Symp 2007;280:108-121; discussion 121-107, 160-104.

35 Cardoso AR, Queliconi BB, Kowaltowski AJ: Mitochondrial ion transport pathways: Role in metabolic diseases. Biochim Biophys Acta 2010;1797:832-838.

36 Rustin P, Munnich A, Rotig A: Succinate dehydrogenase and human diseases: New insights into a wellknown enzyme. Eur J Hum Genet 2002;10:289-291.

37 Cadenas S, Aragones J, Landazuri MO: Mitochondrial reprogramming through cardiac oxygen sensors in ischaemic heart disease. Cardiovascular research 2010;88:219-228. 